\title{
In Vitro Evaluation of Nanochitosan Derivatives and Streptomycin on RD Cell Line and Leishmania Tropica
}

\author{
Ali Shehab Ahmed ${ }^{1 *}$, Muna Mohammed Khayri ${ }^{1}$ and Mohammed M. F. Al-Halbosiy ${ }^{2}$ \\ ${ }^{1}$ College of Biotechnology, University of Al- Nahrian, Baghdad-Iraq. \\ ${ }^{2}$ Biotechnology Research Center, University of Al-Nahrian, Baghdad-Iraq. \\ Corresponding Author: dralishihabahmed@gmail.com.
}

\begin{abstract}
The study aimed to evaluate in vitro the efficiency of the nano-encapsulated streptomycin within carboxymethylnanochitosan synthesized by an acid-base method on Rhabdomyosarcoma RD cell line and Leishmania tropica. Results showed that the concentrations 100 and $50 \mu \mathrm{g} / \mathrm{ml}$ of encapsulated streptomycin were more effective than 50 and $100 \mu \mathrm{g} / \mathrm{ml}$ of streptomycin alone and inhibited the growth of RD cells to 56 and 35 vs. 19.45 and $23 \%$ respectively after 24 hrs of incubation. Carboxymethylnanochitosan at a concentration of $50 \mu \mathrm{g} / \mathrm{ml}$ has the anticancer ability since it inhibited the growth of RD cells up to $20 \%$ in comparison with $19 \%$ for streptomycin at the same concentration. The growth inhibition of $L$. tropica in the presence of streptomycin, carboxymethylnanochitosan and streptomycin encapsulated within carboxymethylnanochitosan at $100 \mu \mathrm{g} / \mathrm{ml}$ for each was 34.4, 36 and $29.5 \%$ respectively. Carboxymethylnanochitosan is then considered the most effective inhibitor of L. tropica growth. [DOI: 10.22401/JNUS.20.4.12]
\end{abstract}

Keywords: Carboxymethylnanochitosan, Encapsulation, RD cell line, Leishmania tropica, Growth Inhibition\%.

\section{Introduction}

The efficiency of many drugs is limited by their prospect to reach the site of action because of different problems like poor bioavailability, solubility, in vivo stability, intestinal absorption, sustained and targeted delivery to the site of action, side effects, therapeutic competence, and fluctuations of drug concentration in plasma which either, drop below the minimum efficacious concentrations or surpass the safe therapeutic concentrations. Mostly a little amount of drug reaches the target site, on the other hand, most of the administered dose distributes throughout the body in accordance with its biological and physicochemical properties [1]. Streptomycin (S) is a water-soluble aminoglycoside derived from Streptomyces griseus and it is commonly referred as sulfate salt of streptomycin. This antibiotic was first isolated in 1943 by Albert Schatz. S binds to the $30 \mathrm{~S}$ ribosome and blocks protein synthesis. Streptomycin also slows down protein synthesis that has already initiated and induces misreading of the mRNA. Streptomycin is used in treating acute infections caused by different types of bacterial strains, such as infections of the respiratory tract (Pneumonia, Bronchitis and
Laryngopharyngitis) and infections of the urinary tract (UTI) [2]. Many of water-soluble derivatives were prepared from chitosan. One of these derivatives is carboxymethyl chitosan (CMC) which has been widely studied because it is simple to synthesize and it is potential of wide of applications [3]. The properties and applications of CMC are relied on its structural characteristics and synthesis, mainly the percentage of substitution and amine location or OH-groups of the carboxymethylation [4]. The active agents can be carried on the surfaces of nanocapsules or embedded in the polymeric membrane [5]. Therapy-loaded polymeric nanocapsules have extended possible applications in the drug delivery systems recently [6]. Polymeric nanocapsules that are a specific kind of polymeric nanoparticles are used to improve biological effects [7]. RD cell line: Rhabdomyosarcoma (RMS) is a malignancy, which arises from skeletal muscle precursors [8]. In children and adolescents less than 20 years old, it is considered the most common kind of soft tissue sarcoma [9]. One of the most common cell lines used in RMS research are RD cells, that can be obtained from ATCC and are grown in Eagle's medium with (10\%) FBS [9]. 
The MTT assay is a colorimetric assay to assess the cell metabolic activity. NAD (P) $\mathrm{H}$-dependent cellular oxidoreductase enzymes may under specific conditions, reflect a number of viable cells that are present. [10]. Therefore, this study was carried out to investigate the efficacy and effect of nanocarboxymethyl nanochitosan as an anticancer and antileishmania when carried with streptomycin, compared to antibiotic alone. Different concentrations 50 and $100 \mu \mathrm{g} / \mathrm{ml}$ of CMNC-S, streptomycin alone and CMNC were prepared and the inhibitory effect was tested on RD cell line and L. tropica.

\section{Materials and Methods}

Streptomycin: powder was purchased from a local pharmacy. Two concentrations (50 and $100 \mu \mathrm{g} / \mathrm{ml}$ ) were prepared in sterile deionized water.

Preparation of CMNC [11]: Nanochitosan (3g) was dissolved in $65 \mathrm{ml}$ of isopropanol. After stirring for 20 minutes at room temperature, $20.4 \mathrm{~g}$ of $40 \%$ aqueous $\mathrm{NaOH}$ and $14.4 \mathrm{~g}$ of monochloroacetic acid/ isopropanol solution $(1: 1 \mathrm{v} / \mathrm{v})$ were melted together and added to the suspension. The reaction continued at room temperature for $24 \mathrm{hrs}$. The product was centrifuged at $14000 \mathrm{rpm}$ for 10 minutes using a high-speed cooling centrifuge and suspended in $150 \mathrm{ml}$ of methanol then, neutralized by glacial acetic acid. Finally, the product was washed with $80 \%$ ethanol and dried at room temperature.

Preparation of CMNC-S: CMNC-S was prepared by mixing $14.4 \mathrm{~g}$ of monochloroacetic acid/ isopropanol solution (1:1 v/v), $20.4 \mathrm{~g}$ of $40 \%$ aqueous $\mathrm{NaOH}$ with Nanochitosan-Isopropanol solution. Then streptomycin at a ratio 1:5 was added and mixed well for $24 \mathrm{hrs}$ at room temperature. The solution was centrifuged at $14000 \mathrm{rpm}$ for 10 minutes using a high-speed cooling centrifuge. The supernatant was discarded and the deposit was suspended with methanol and then neutralized with $10 \%$ glacial acetic acid. Finally, the deposit was washed with ethanol $(80 \%)$ and dried at room temperature.

In Vitro Anticancer Activity: The anticancer efficacy of S, CMNC and CMNC-S against $\mathrm{RD}$ cell line was evaluated. The colorimetric cell viability MTT assay was used as described by $[12,13]$. Aliquot of $100 \mu \mathrm{l}$ of RD cells $\left(10^{6} \mathrm{cell} / \mathrm{ml}\right)$ was dispensed using 96-well tissue culture plates. Two concentrations of $\mathrm{S}$, CMNC, CMNC-S (50 and $100 \mu \mathrm{g} / \mathrm{ml}$ ) were prepared by dissolving in sterile distilled Water (DW). Aliquots of $100 \mu \mathrm{l}$ of various concentrations were added to each well and incubated for $24 \mathrm{hrs}$ at $37^{\circ} \mathrm{C}$. After that, $10 \mu \mathrm{l}$ of MTT solution $(5 \mathrm{mg} / \mathrm{ml})$ was added to the wells and incubated for $4 \mathrm{hrs}$ at $37^{\circ} \mathrm{C}$. Then, $50 \mu$ of dimethyl sulfoxide (DMSO) was added to the wells and incubated for 10 minutes. RD cells were cultured in the medium without $\mathrm{S}, \mathrm{CMNC}$ and CMNC-S as a positive control (AC), and the medium without cells and test solutions as a blank. The absorbance of each well was read at $620 \mathrm{~nm}$ by using an ELISA reader. The inhibition percentage was calculated according to the following equation:

$$
\text { Inhibition }(\%)=(\mathrm{AC}-\mathrm{AS} / \mathrm{AC}) \times 100
$$

Where (AC) and (AS) are the optical density for positive control and tested samples respectively.

In Vitro antileishmanial activity: The antileishmanial efficiency of S, CMNC and CMNCS against promastigote forms of $L$. tropica was assayed. The colorimetric cell viability MTT assay was used as follows [14]:

L. tropica promastigotes were cultured in 96-well tissue culture plate $100 \mu \mathrm{L}$ well $\left(10^{6}\right.$ parasite $\mathrm{ml}^{-1}$ ), then a $100 \mu \mathrm{L}$ of various concentrations of S, CMNC and CMNC-S test solutions were prepared ( 50 and $100 \mu \mathrm{g} / \mathrm{ml}$ ) by dissolving in sterile distilled water and added to each well then incubated for $4 \mathrm{hrs}$ at $26^{\circ} \mathrm{C}$. After that, $50 \mu \mathrm{L}$ of (DMSO) was added to the wells and incubated for 10 minutes. Promastigotes were cultured in the medium without S, CMNC and CMNC-S as a positive control, and the medium without promastigotes and test solutions as a blank. Finally, the absorbance was read at $620 \mathrm{~nm}$ for each well by using an (ELISA) reader. Finally, the living promastigotes, the viability and inhibition percentage were calculated using the same equation that used for RD cell line. 


\section{Results and Discussion}

Caroxymehtylnanochitosan (CMNC)

CMNC was prepared according to [11]. The steps included except that filtration were substituted with centrifugation at high speed under cooling to obtain a good yield. Because of the low solubility of chitosan or nanochitosan when $\mathrm{pH}$ is more than 6.5 and this represent a serious barrier in many of its possible applications and the CMNC is soluble in a wide range of $\mathrm{pH}$ mentioned by Fernanda and Campana-Filho (2005). The yield was $420 \mathrm{mg}$ dry weight of CMNC from $3 \mathrm{~g}$ of $\mathrm{NC}$ The supernatant of centrifugation was maintained for subsequent experiments.

\section{Caroxymehtylnanochitosan loaded with Streptomycin}

The ratio $1: 5 \mathrm{w} / \mathrm{w}$ of $(\mathrm{CMN}: \mathrm{S})$ was added to one portion of CMNC during the preparation of CMNC based on the dry weight of the CMNC produced by the method of preparation and after the addition of solvents ensuring the loading of the $\mathrm{S}$ within the structure of CMNC to obtain formula of encapsulation and surface attachment. The subsequent steps of preparing CMNC were followed. The supernatant of centrifugation was maintained for subsequent experiments of loading efficiency $\%$.

\section{In vitro inhibitory effect on $\mathrm{RD}$ cell line}

Results showed that the inhibitory effect of CMNC-S at $50 \mu \mathrm{g} / \mathrm{ml}$ was significantly high $(35.5 \pm 4.40) \%$ followed by CMNC $(20.55 \pm 2.65)$ and $S(19.45 \pm 1.55)$ respectively. In addition, the inhibitory effect of CMNC-S at $100 \mu \mathrm{g} / \mathrm{ml}$ was $56.0 \pm 1 \%$ followed by CMNC (16.02 \pm 5.06$)$ and S $(22.98 \pm 12.02)$ respectively. The Table (1) show that the best treatment was CMNC-S at concentration $100 \mu \mathrm{g} / \mathrm{ml}$ where the growth inhibition was $56 \%$, compared with $23 \%$ of $\mathrm{S}$ at the same concentration. In addition to $50 \mu \mathrm{g} / \mathrm{ml}$ of CMNC-S. Note that the loading efficiency was $90 \%$ means the real concentration $45 \mathrm{mg} / \mathrm{ml}$. The growth inhibition for CMNC-S (100 $\mu \mathrm{g} / \mathrm{ml}$ ) approximated $50 \mu \mathrm{g} / \mathrm{ml}$ and this may due to the mechanism of the $S$ release, which almost the same rate within only 24 hours of culture incubation. Therefore, prolonging the incubation time increases the percentage of inhibition based on the sentiments [14]. It was found that carboxymethylnanochitosan

at the concentration $50 \mu \mathrm{g} / \mathrm{ml}$ has anticancer ability since it inhibited the growth of RD cells to $20 \%$ in comparison with $19 \%$ for streptomycin at the same concentration.

\section{Table (1) \\ In vitro inhibitory effect of CMNC and CMNC-S on RD cell line.}

\begin{tabular}{||c||c||}
\hline $\begin{array}{c}\text { Treatment } \\
(\boldsymbol{\mu g} / \mathbf{m l})\end{array}$ & $\begin{array}{c}\text { \% growth Inhibition } \\
(\text { PGI \% Mean } \pm \text { SE) }\end{array}$ \\
\hline \hline $\mathrm{S}(50)$ & $19.45 \pm 1.55$ \\
\hline S $(100)$ & $22.98 \pm 12.02$ \\
\hline CMNC (50) & $20.55 \pm 2.65$ \\
\hline \hline CMNC $(100)$ & $16.02 \pm 5.06$ \\
\hline \hline CMNC-S (50) & $35.5 \pm 4.40$ \\
\hline \hline CMNC-S (100) & $\mathbf{5 6 . 0} \pm \mathbf{1}$ \\
\hline
\end{tabular}

*S:Streptomycin; CMNC: Carboxymethyl nanochitosan.

\section{In vitro inhibitory effect on Leishmania tropica.}

The inhibitory effect CMC at $50 \mu \mathrm{g} / \mathrm{ml}$ was a significant $(23.3 \pm 0.007) \%$ followed by CMNC-S (24.8 \pm 0.012$)$ and $S(35.5 \pm 0.014)$ respectively. In addition, the inhibitory effect of $\mathrm{CMNC}$ at $100 \mu \mathrm{g} / \mathrm{ml}$ was significantly higher (36)\% than others. Streptomycin and encapsulated streptomycin were (34.4 and $29.5) \%$ respectively. Nanochitosan derivatives and streptomycin effect on the growth of $L$. tropica was exhibited in the Table (1). The growth inhibition of L. tropica in presence of $\mathrm{S}, \mathrm{CMNC}$ and CMNC-S at $100 \mu \mathrm{g} / \mathrm{ml}$ for each was $34.4,36$ and $29.5 \%$ respectively. CMNC is then considered the most effective inhibitor on the growth of L. tropica.

Table (2)

In vitro inhibitory effect of nanochitosan derivatives and antibiotic on Leishmania tropica.

\begin{tabular}{|c||c|}
\hline $\begin{array}{c}\text { Treatment* } \\
(\boldsymbol{\mu g} / \mathbf{m l})\end{array}$ & $\begin{array}{c}\text { \% growth Inhibition } \\
(\text { PGI \% Mean } \pm \text { SE) }\end{array}$ \\
\hline \hline S (50) & $35.5 \pm 0.014$ \\
\hline S $(100)$ & $34.4 \pm 0.009$ \\
\hline CMNC (50) & $23.3 \pm 0.007$ \\
\hline \hline CMNC (100) & $36 \pm 0.004$ \\
\hline CMNC-S (50) & $24.8 \pm 0.012$ \\
\hline CMNC-S (100) & $29.5 \pm 0.002$ \\
\hline
\end{tabular}

*S:Streptomycin; CMNC: Carboxymethyl nanochitosan. 


\section{Acknowledgment}

I extend my sincere thanks and gratitude to Professor Dr. Kadhim Ibrahim (the University of Al- Nahrian, College of Biotechnology) for revising the English language and assistant professor Shahla (the University of Al-Nahrian, College of Biotechnology) for her technical assistance.

\section{References}

[1] Ochekpe N., Olorunfemi P. and Ngwuluka N. "Nanotechnology and Drug Delivery Part 1: Background and Applications", Tropical Journal of Pharmaceutical Research, 8(3), 265-27, 2009.

[2] Amano S., Miyadoh S. and Shomura T., Streptomyces griseus M-1027. Digital Atlas of Actinomycetes, 2008.

[3] Mourya V. K. and Inamdar N. N. J. "Trimethyl chitosan and its applications in drug delivery", J Mater Sci Mater Med, 20(5), 1057-1079, 2009.

[4] Fernanda R. and Campana-Filho P. "Preparation and Characterization of Carboxymethylchitosan", Ciência e Tecnologia, 15(2), 79-83, 2005.

[5] Khoee S., Yaghoobian M., "An investigation into the role of surfactants in controlling particle size of polymeric nanocapsules containing pencillin-G in double emulsion", Eur. J. Med. Chem, 44, 2392-2399, 2009.

[6] Rong X., Xie Y., Hao X., Chen T., Wang Y. and Liu Y., "Application of polymeric nanocapsules in field of drug delivery systems", Curr Drug Discov Technol, 8(3), 173-187, 2011.

[7] Frank L. A., Contri R. V., Beck R.C.R., Pohlmann A. R. and Guterres S. S., "Improving drug biological effects by nanocapsulation into polymeric nanocapsules", Nanobiotechnol, 7(5), 623639, 2015.

[8] Saab R., Spunt S.L. and Skapek S.X., "Myogenesis and rhabdomyosarcoma the Jekyll and Hyde of skeletal muscle", Curr Top Dev Biol, 94, 197-234, 2011.

[9] Ognjanovic S., Linabery A.M., Charbonneau B. and Ross J.A., "Trends in childhood rhabdomyosarcoma incidence and survival in the United States, 19752005”. Cancer, 115 (18), 4218-4226, 2009.
[10] van der Meide W. F., Jensema AJ., Akrum RA., Sabajo LO., Lai A., Fat RF. and Lambregts L., "Epidemiology of cutaneous leishmaniasis in Suriname: A study performed in 2006", Am J Trop Med Hy, 79 (2),192-197, 2008.

[11] Zeenat M.A., Laghari A., Ansari A. and Khuhawar M.Y., "Synthesis and Characterization of Carboxymethyl Chitosan and its Effect on Turbidity Removal of River Water", IOSR Journal of Applied Chemistry (IOSR-JAC), 5(3), 7279, 2013.

[12] Kang M.H., Smith M.A., Morton C.L., Keshelava N., Houghton P.J.and Reynolds C.P., "National Cancer Institute pediatric preclinical testing program: model description for in vitro cytotoxicity testing", Pediatric Blood \& Cancer, 56(2), 239-249, 2011.

[13] Chih P.L., Wei J.T., Yuang L.L. and Yuh C.K., "The extracts from Nelumbonucifera suppress cell cycle progression, cytokine genes expression, and cell proliferation in human peripheral blood mononuclear cells", Life Sci, 75, 699-716, 2004.

[14] Mahmoudvand H., Ezzatkhah F. and Sharififar F., "Antileishmanial and cytotoxic effects of essential oil and methanolic extract of Myrtus communis L". Korean J. Parasitol, 53(1), 21-27, 2015.

[15] Merlen T., Sereno D., Brajon N., Rostand F. and Lemesre GL., "Leishmania spp: completely defined medium without serum and macromolecules (CDM/LP) for the continuous in vitro cultivation of infective promastigote forms", Am. J. Trop. Med. Hyg, 60(1), 41-50, 1999. 